\title{
DEVELOPMENT AND COMPARATIVE STUDY OF INDUCTION MACHINE BASED DYNAMIC P, Q LOAD MODELS
}

\author{
B.C. Lesieutre P.W. Sauer M.A. Pai \\ (Member) (Fellow) (Fellow) \\ Department of Electrical and Computer Engineering \\ University of Illinois at Urbana-Champaign \\ 1406 W. Green St. Urbana, Il 61801
}

\begin{abstract}
In this paper we develop a $P, Q$ lond model from a third-order induction motor model. This load model is expressed in terms of meaningful bus quantities: voltage magnitude, angle, frequency, active and reactive powers. From this general model, all induction machine based dynamic $P, Q$ load models may be derived. We also address issues associated with the implementation of implicitly defined load models.

key words: Load modeling, dynamic analysis, induction motors.

\section{Introduction}

There is a need to include detailed load models in power system small-signal and transient stability studies. This need for moteling research has become apparent as traditional models are not aclecuate to describe all events that occur under heavily loaded conditions. This was made clear by the Swedish blackout of 1983 , after which a stability study was unable to account for the event [1]. The conclusion reached by the investigators was that more detailed modeling of power systems is required; including load characteristics, tap changing transformers, generalor current limiters, and the action of protective relays. This paper deals with certain load models that capture some plysical properties of loads. This is important in studies of stressed power systems.

One problem with the development of load models is the difficully in making measurements, particularly obtaining load cata ontside the nomal operating range. Despite this difficulty, new load models have been proposed $[2,3,4,5,6,7]$. Some of these are based on the assumption that load recovery is exponential in nature $[4,5]$. There is some evidence of this in londs that are thermally related. Some models mote that the steady-state characteristics may be significantly different than the transient behavior [5, 6]. Given a general model, presumably one can make measurements to obtain the parameters. However, this is not easily accomplished over the wide range of system slates possible during disturbances.
\end{abstract}

94 WM 166-9 PWRS A paper recommended and approved by the IEEE Power System Engineering Committee of the IEEE Power Engineering Society for presentation at the IEEE/PES 1994 Winter Meeting, New York, New York, January 30 - February 3, 1994. Manuscript submitted July 30 , 1993; made available for printing

January 14, 1994.
Another approacl is to make assumptions abont the load composition and attempt to capture some of the physical characteristics of such elements. For example, noting that induction motors constitute a large portion of the load, many researchers suggest the use of induction motor dynamic modchs to capture loaxl dynamics. Such a model can cuptinte some of the basic dynamics involving the energy stored in the indurtion motors in the system. Of course, one could not claim that such a model will exactly capture load dyuamics, mather that it might represent some basic phenomena involving induction motors better than traditional models.

The problems with simply using an induction motor model as a load are that it increases the size of the dynamic system, which complicates the analysis; and that the traclitional induction motor variables lack physical signilicance in a power system. For instance, using an incluction motor model at a bus means that the bus las a certain "slip"; it is not clear how to define or neasure such a slip. It is clesirable then to have it model that is represented by measurable bus cumntities such as voltage, current, power. and freumency. A model in lems of such variables based on induction motor characteristics wonth be useful for power system analysis.

In this paper we examine some of the lond models that have been suggested in the literature that are based on induction motor characteristics. Starting with a thirel-order dymanic model of an induction motor, we derive a dynamic model in terms of meaningful bus variables: $P, Q, V, \theta$, ancl $\omega$ (lice quency). We show which assumptions are necessary to croul the models that exist in the literature. Inderstanding these. assumptions is essential to properly entoloy these models.

\section{Dynamic models that appear in the literature}

Some transient stability programs allow the nse of a detailed induction motor load including rotor flux and shaft dymasnics [8]. Although these models capture induction motor dynamic: characteristics, they lack meaning at the power system level. Power engineers tend to think in terms power demnind and voltages. It is undesirable to associate fluxes and slip with a given bus. 'The following models are dynamic $P, Q$ models based on induction motors.

In the EPRI LOADSYN program the general "static" lond model is [9]

Model A:

$$
\begin{aligned}
& P_{L}=P_{1} V^{k_{p 1}}\left(1+K_{p f 1} \Delta f\right)+P_{2} V^{k_{p 2}} \\
& Q_{L}=Q_{1} V^{k_{11}}\left(1 .+K_{q f 1} \Delta f\right)+Q_{2} V^{k_{22}}\left(1+K_{q f 2} \Delta f\right)(2)
\end{aligned}
$$

0885-8950/95/\$04.00 (C) 1994 IEEE 
where $\Delta f$, the change in frequency, is determined from the time rale of change of the angle of the bus voltage. Since this model is frequency-dependent it is not really a static model. The first term in Equation (1) is used to represent frequency-dependent loads including motors. The second term is static, used to represent the resistive part of the load. The first term in Equation (2) represents the reactive consumption of the load. The second term represents reactive compensation and losses in the subl.ransmission system. It is interesting that induction motors are modeled (crudely) by a function exponentially related to the voltage magnitude and linearly related to frequency variations. The EPRI LOADSYN program also includes a more detailed induction motor model which consists of an equivar lent circuit and a differential equation representing the torque equation [9].

After the blackout of 1983 . Swedish researchers obtained the following limear load model based on measurements and simulations of induction motors [2].

Model B:

$$
\begin{aligned}
\Delta P_{L} & =K_{p f} \Delta f+K_{p v}\left(\Delta V+T_{p v} \frac{d V}{d t}\right) \\
\Delta Q_{L} & =K_{q f} \Delta f+K_{q v} \Delta V
\end{aligned}
$$

Note that the active power is a function of the time derivative of the voltage magnitude. 'The constant $T_{p v}$ is said to be related in part to the inertia of the motor. This model has been used in voltage collapse stindies [10].

A different, model, based on physical intuition and supported by simulalion, is proposed in [T],

Model C:

$$
\begin{aligned}
P_{L} & =P_{\text {stat }}(V) \\
Q_{L} & =Q_{\text {atat }}(V)+K(V) \frac{d V}{d t}
\end{aligned}
$$

where $\boldsymbol{P}_{\text {atat }}$ and $\boldsymbol{Q}_{\text {atat }}$ are the steady-state active and reactive power/voltage characteristics. Now the reactive power is related to the time derivative of the voltage magnitude. This Inodel also has been used in vollage stability studies [7].

It is important to note that these two models are fundamentally different. The former relates active power to the time derivative of the voltage magnitude whereas the latter relates reactive power to the time derivative of the voltage magnitude. Such an apparent discrepancy indicates the need for further theoretical research.

A model encompassing Model $\mathrm{C}$ is given in [3]

Molel D:

$$
\begin{aligned}
P_{L} & =P_{0}+K_{p f} \frac{d \theta}{d t} \\
Q_{L} & =Q_{o}(V)+\epsilon^{\prime} V \frac{d V}{d t}
\end{aligned}
$$

where $d \theta / d t$ is the frequency deviation from nominal. Using the argmment that active power load is largely unaffected by changes in voltage magnitude, it is modeled as a function of frequency. 'The reactive power is assumed to be affected by the bus voltage dynamics. Althongh this model does not originate from induction motor assumptions, it does relate the active and reactive powers to vollage magnitude and frequency. This model has been used in voltage collapse studies [11]. The active load relation given in this model is originally presented in [12].

An implicitly defined model in which voltage and power derivatives appear is given in [4].
Model E:

$$
\begin{aligned}
T_{p p} \frac{d P_{L}}{d t}+P_{L} & =P_{o}(V)+K_{p}(V) \frac{d V}{d t} \\
T_{q p} \frac{d Q_{L}}{d t}+Q_{L} & =Q_{o}(V)+K_{q}(V) \frac{d V}{d t}
\end{aligned}
$$

This model captures post-disturlance dyuamics by an exponential recovery to the stendy-state values. With the uppropriate assumptions, this model encompasses both Models is and $C$.

A "generic" model which also captures power recovery is given in [5]:

Model F:

$$
\begin{aligned}
T_{p} \frac{d x}{d t} & =P_{s}(V)-P, & P & =x P_{t}(V) \\
T_{q} \frac{d y}{d t} & =Q_{\lrcorner}(V)-Q, & Q & =y Q_{T}(V)
\end{aligned}
$$

This is an extension of the "adaptive" load in [16]. 'This model emphasizes that the load transient power/voltage relation, $x P_{t}(V)$, can be significantly different from the static power/voltage relation, $P_{a}(V)$. A special case where the load is constant power in steady state $\left(P_{s}(V)\right.$ and $Q_{0}(V)$ ase constants) and a constant impedance transiently $\left(P_{t}(V)=\right.$ $\left.Q_{t}(V)=V^{2}\right)$ is examined in [6]. Additional work on this model is reported in $[1 T, 18]$.

\section{Third-order induction motor model}

To better understand the preceding induction motor-based dynauic load models, the third-order induction motor modclad used in this paper is developed. Consider the following trauli tional fifth-order induction machine model in the we reference frame (in per unit):

$$
\begin{aligned}
& \frac{1}{\omega_{s}} \frac{d \psi_{D}}{d t}=-R_{s} I_{D}+\frac{\omega_{e}}{\omega_{s}} \psi_{Q}+V_{D}, \\
& \frac{1}{\omega_{s}} \frac{d \psi_{Q_{1}}}{d t}=-R_{1} I_{Q_{0}}-\frac{\omega_{e}}{\omega_{s}} \psi_{D_{0}}+V_{Q}, \\
& \frac{1}{\omega_{c}} \frac{d \psi_{D_{r}}}{d t}=-R_{r} I_{D_{r}}+\frac{\omega_{e}-\omega_{r}}{\omega_{s}} \psi_{Q_{r}} \\
& \frac{1}{\omega_{s}} \frac{d \psi_{Q r}}{d t}=-R_{r} I_{Q r}-\frac{\omega_{e}-\omega_{r}}{\omega_{s}} \psi_{D_{r}} \\
& \frac{2 H}{\omega_{Q}} \frac{d \omega_{r}}{d t}=-T_{L}+\left(\psi_{Q_{r}} I_{D_{r}}-\psi_{D r} I_{Q_{r}}\right)
\end{aligned}
$$

where $\omega_{s}$ is the base frequency used in the per-unit scaling and $\omega_{e}$ is the frequency of the "QDO" transformation. We consider the reference frame in which $\omega_{e}=\omega_{s}$. The variables $\psi_{D} . \psi_{Q s}$ $\psi_{D_{r}}$, and $\psi_{Q_{r}}$ are the stator and rotor fluxes, and $\omega_{r}$ is 1.he rotational speed. The fuxes are related to the currents $\mathrm{b}$

$$
\begin{aligned}
& {\left[\begin{array}{l}
\psi_{D,} \\
\psi_{D r}
\end{array}\right]=\left[\begin{array}{ll}
X_{s} & X_{m} \\
X_{m} & X_{r}
\end{array}\right]\left[\begin{array}{l}
I_{D,} \\
I_{D_{r}}
\end{array}\right]} \\
& {\left[\begin{array}{l}
\psi_{Q v} \\
\psi_{Q r}
\end{array}\right]=\left[\begin{array}{ll}
X_{*} & X_{m} \\
X_{m} & X_{r}
\end{array}\right]\left[\begin{array}{l}
I_{Q \bullet} \\
I_{Q r}
\end{array}\right]}
\end{aligned}
$$

In almost all cases the stator winding dynamics are neglested. Their dynamics are fast and slould be included in studies that also include transmission line dyuanics. Neglecting stator transients and resistance, the stator algebraic equalions arc

$$
\begin{aligned}
& 0=\psi_{Q_{A}}+V_{D_{\bullet}} \\
& 0=-\boldsymbol{\psi}_{D_{0}}+V_{Q_{2}}
\end{aligned}
$$


184

Define

$$
\begin{aligned}
X^{\prime} & =\frac{X, X_{r}-X_{m}^{2}}{\bar{X}_{r}} \\
E_{D}^{\prime} & =-\frac{X_{m}}{\bar{X}_{r}} \psi_{Q r} \\
E_{Q}^{\prime} & =\frac{X_{m}}{X_{r}} \psi_{D r} \\
T_{0}^{\prime} & =\frac{X_{r}}{\omega_{s} R_{r}} \\
s & =\frac{\omega_{s}-\omega_{r}}{\omega_{s}}
\end{aligned}
$$

A thircl-order induction machine model can be written as Stator:

$$
\begin{aligned}
& V_{D_{1}}=E_{D}^{\prime}-X^{\prime} I_{Q}, \\
& V_{Q}=E_{Q}^{\prime}+X^{\prime} I_{D},
\end{aligned}
$$

Rotor fluxes:

$$
\begin{aligned}
& T_{0}^{\prime} \frac{d E_{Q}^{\prime}}{d t}=-E_{Q}^{\prime}+\frac{X_{m}^{2}}{X_{r}} I_{D}-s \frac{X_{r}}{R_{r}} E_{D}^{\prime} \\
& T_{o}^{\prime} \frac{d E_{D}^{\prime}}{d t}=-E_{D}^{\prime}-\frac{X_{m}^{2}}{X_{r}} I_{Q}+s \frac{X_{r}}{R_{r}} E_{Q}^{\prime}
\end{aligned}
$$

Torque equation

$$
2 H \frac{d s}{d t}=T_{L}-\left(E_{Q}^{\prime} I_{Q},+E_{D}^{\prime} I_{D,}\right)
$$

Assuming the mechanical load torque is linear in speed.

$$
\begin{aligned}
T_{L} & =K_{0} \omega_{r} \\
& =K_{0} \omega_{0}(1-s) \\
& =K_{L}(1-s)
\end{aligned}
$$

the torque equation is writ.ten

$$
2 H \frac{d s}{d t}=K_{L}(1-s)-\left(E_{Q}^{\prime} I_{Q_{1}}+E_{D}^{\prime} I_{D_{0}}\right)
$$

Equations (25)-(30) and (33) represent the induction motor model used in the following sections. A load torque that is linear in speed is chosen deliberately to model the tests performed in [2] in which a linear load torque was applied.

\section{General induction motor based load model}

It is desirable to have a single, general load based on an induction motor. In this section, such a model is developed without making drastic assumptions. The goal is to achieve a model expressed only in terms of meaningful bus variables: active and reactive powers: vollage magnitude, angle, and frequency.

Begin with the third-order model $(2 \pi)-(30)$ and (33). The clesired model is obtained in terms of bus variables by performing the following four variable transformations:

1. Itse the stator algebraic Equations $(27)-(28)$ to replace $E_{D}^{\prime}$ and $E_{Q}^{\prime}$ with $V_{D}$ and $V_{Q}$.

2. Express the vollage in polar coordinates. $V_{D}+j V_{Q}=$ $V e^{j \theta}$.

3. Replace the current variables, $I_{D}$ and $I_{Q}$, with the aclive and reactive powers, and the voltage magnitude and angle, $P_{L}, Q_{L}, V$, and $\theta$, using

$$
\begin{aligned}
& P_{L}=V \cos \theta I_{D_{1}}+V \sin \theta I_{Q .} \\
& Q_{L}=V \sin \theta I_{D_{L}}-V \cos \theta I_{Q} .
\end{aligned}
$$

4. Replace the slip variable with an electrical frequency variable. The transformation used to accomplish this will he discussed in greater detail in the text.

The first transformation eliminates the internal voltage variables, $E_{D}^{\prime}$ and $E_{Q}^{\prime}$, using Equations (2T) and (28). The rexult. ing model is in terms of voltage. current. and slip:

$$
\begin{aligned}
& T_{o}^{\prime} \frac{d V_{D}}{d t}=-V_{D}+s \frac{X_{r}}{R_{r}} V_{Q} \\
& -s \frac{X_{T}}{R_{r}} X^{\prime} I_{D_{s}}-X, I_{Q},-X^{\prime} T_{o}^{\prime} \frac{d I_{Q}}{d t} \\
& T_{\circ}^{\prime} \frac{d V_{Q}}{d t}=-V_{Q}-s \frac{X_{r}}{R_{r}} V_{D} \\
& +X_{\iota} I_{D_{s}}-s \frac{X_{r}}{\bar{R}_{r}} X^{\prime} I_{Q}+X^{\prime} T_{\circ}^{\prime} \frac{d I_{D s}}{d t} \\
& 2 H \frac{d s}{d t}=K_{L}(1-s)-\left(V_{D} I_{D}+V_{Q} I_{Q}\right)
\end{aligned}
$$

The second transformation expresses the voltage in polir coordinates, The model is now written

$$
\begin{aligned}
T_{0}^{\prime} \frac{d V}{d t}= & -V+X_{s}\left(I_{D}, \sin \theta-I_{Q} \cos \theta\right) \\
& -s \frac{X_{r}}{R_{r}} X^{\prime}\left(I_{D_{s}} \cos \theta+I_{Q_{0}} \sin \theta\right) \\
& +X^{\prime} T_{o}^{\prime}\left(\frac{d I_{D_{1}}}{d t} \sin \theta-\frac{d I_{Q_{s}}}{d t} \cos \theta\right) \\
T_{0}^{\prime} V \frac{d \theta}{d t}= & -s \frac{X_{r}}{\bar{R}_{r}} V+X_{0}\left(I_{D}, \cos \theta+I_{Q_{s}} \sin \theta\right) \\
& +s \frac{X_{r}}{R_{r}} X^{\prime}\left(I_{D}, \sin \theta-I_{Q_{0}} \cos \theta\right) \\
& +X^{\prime} T_{0}^{\prime}\left(\frac{d I_{D},}{d t} \cos \theta+\frac{\left.d I_{Q_{s}} \sin \theta\right)}{d t} \sin \right) \\
2 H \frac{d s}{d t}= & K_{L}(1-s)-V\left(I_{D} \cos \theta+I_{Q} \sin \theta\right)
\end{aligned}
$$

The third transformation replaces the current. variables with real and reactive powers using Equations (34) and (35). 'I'h model becomes

$$
\begin{aligned}
T_{0}^{\prime} \frac{d V}{d t}= & -V+\frac{X_{\dot{ }}}{V} Q_{L}-s \frac{X_{r}}{R_{r}} \frac{X^{\prime}}{V} P_{L} \\
& +\frac{X^{\prime}}{V} T_{o}^{\prime}\left(\frac{d Q_{L}}{d t}-\frac{Q_{L}}{V} \frac{d V}{d t}-P_{L} \frac{d \theta}{d t}\right) \\
T_{0}^{\prime} V \frac{d \theta}{d t}= & -s \frac{X_{r}}{R_{r}} V+\frac{X_{1}}{V} P_{L}+s \frac{X_{r}}{R_{r}} \frac{X^{\prime}}{V} Q_{L} \\
& +\frac{X^{\prime}}{V} T_{o}^{\prime}\left(\frac{d P_{L}}{d t}-\frac{P_{L}}{V} \frac{d V}{d t}+Q_{L} \frac{d \theta}{d t}\right) \\
2 H \frac{d s}{d t}= & K_{L}(1-s)-P_{L}
\end{aligned}
$$

In this model, all of the variables except slip are the desimel bus variables. This model is implicilly defined with the derivatives of the voltage, angle, active power and reactive power. The fourth and lust step is to introduce a change of variables from slip to frequency. This transformation is not obvious. 
Equations (42) and (43) are solved explicitly for the derivalives of the voltage and angle. The model is

$$
\begin{gathered}
\left(1-\frac{X^{\prime 2}}{V^{4}}\left(P_{L}^{2}+Q_{L}^{2}\right)\right) T_{\circ}^{\prime} \frac{d V}{d t}= \\
-V+\left(X^{\prime}+X_{0}\right) \frac{Q_{L}}{V}-\frac{X^{\prime} X}{V^{3}}\left(P_{L}^{2}+Q_{L}^{2}\right) \\
+\frac{X^{\prime} T_{0}^{\prime}}{V}\left(\left(1-\frac{X^{\prime}}{V^{2}} Q_{L}\right) \frac{d Q_{L}}{d t}-\frac{X^{\prime}}{V^{2}} P_{L} \frac{d P_{L}}{d t}\right)(45) \\
\left(1-\frac{X^{\prime 2}}{V^{4}}\left(P_{L}^{2}+Q_{L}^{2}\right)\right) T_{0}^{\prime} V \frac{d \theta}{d t}= \\
-s \frac{X_{r}}{R_{r}} V+\left(X^{\prime}+X_{\bullet}\right) \frac{P_{L}}{V}+s \frac{X^{\prime} 2}{V^{3}} \frac{X_{r}}{R_{r}}\left(P_{L}^{2}+Q_{L}^{2}\right) \\
+\frac{X^{\prime} T_{0}^{\prime}}{V}\left(\left(1+\frac{X^{\prime}}{V^{2}} Q_{L}\right) \frac{d P_{L}}{d t}-\frac{X^{\prime}}{V^{2}} P_{L} \frac{d Q_{L}}{d t}\right)(46) \\
2 H^{\frac{d s}{d t}}=K_{L}(1-s)-P_{L}
\end{gathered}
$$

The key is in Equation (46). Recalling that $T_{o}^{\prime}=X_{r} / \omega, R_{r}$ Equation 16 can be written as

$$
\begin{aligned}
(1 & \left.-\frac{X^{\prime 2}}{V^{4}}\left(P_{L}^{2}+Q_{L}^{2}\right)\right) T_{0}^{\prime} V \frac{d \theta}{d t}= \\
& -\left(1-\frac{X^{\prime 2}}{V^{4}}\left(P_{L}^{2}+Q_{L}^{2}\right)\right) T_{0}^{\prime} V_{s \omega_{0}}+\left(X^{\prime}+X_{0}\right) \frac{P_{L}}{V} \\
& +\frac{X^{\prime} T_{0}^{\prime}}{V}\left(\left(1+\frac{X^{\prime}}{V^{2}} Q_{L}\right) \frac{d P_{L}}{d t}-\frac{X^{\prime}}{V^{2}} P_{L} \frac{d Q_{L}}{d t}\right)
\end{aligned}
$$

'Thus,

$$
\begin{aligned}
& \frac{d \theta}{d t}=-s \omega_{s} \\
& +\frac{\left(X^{\prime}+X_{0}\right) \frac{P_{L}}{V}+\frac{X^{\prime} T_{0}^{\prime}}{V}\left(\left(1+\frac{X^{\prime}}{V^{2}} Q_{L}\right) \frac{d P_{L}}{d t}-\frac{X^{\prime}}{V^{2}} P_{L} \frac{d Q_{L}}{d t}\right)}{\left(1-\frac{X^{\prime} 2}{V^{\prime}}\left(P_{L}^{2}+Q_{L}^{2}\right)\right) T_{0}^{\prime} V}
\end{aligned}
$$

Define frequency deviation at the bus to be the time derivative of the angle.

$$
\omega=\omega_{,}+\frac{d \theta}{d t}
$$

Thus,

$$
\frac{d \theta}{d t}=\omega-\omega,
$$

It is critical to note that this is an electrical frernuency. Fynating Equations (49) and (50) gives the desired transformation:

$$
\begin{aligned}
& \frac{\omega}{\omega_{s}}=(1-s) \\
& +\frac{\left(X^{\prime}+X_{0}\right) \frac{P_{L}}{V}+\frac{X^{\prime} r_{o}^{\prime}}{V}\left(\left(1+\frac{X^{\prime}}{V^{2}} Q_{L}\right) \frac{d P_{L}}{d t}-\frac{X^{\prime}}{V j} P_{L} \frac{d Q_{L}}{d t}\right)}{\left(1-\frac{X^{\prime}}{V}\left(P_{L}^{2}+Q_{L}^{2}\right)\right) T_{o}^{\prime} \omega \cdot V}(52) \\
& =(1-s) \\
& +\frac{\left(X^{\prime}+X_{0}\right) P_{L} V^{2}+X^{\prime} T_{o}^{\prime}\left(\left(V^{2}+X^{\prime} Q_{L}\right) \frac{d P_{L}}{d t}-X^{\prime} P_{L} \frac{d Q_{L}}{d t}\right)}{\left(V^{4}-X^{\prime 2}\left(P_{L}^{2}+Q_{L}^{2}\right)\right) \frac{X_{L}}{R_{r}}}(5.3)
\end{aligned}
$$

Using this transformalion elininates the slip variable. The resulting load model is given by Equations (54)-(56).

The key point is that this model is an exact t.ransformmtion of the original model. The ouly assumptions made were neglecting stator resistance and assuming mechanical torcune proportional to speed. Since this model is implicit and very nonlinear, one would not want to implement it. Mather. it importance is in allowing clear derivation of all simpler models, allowing the user to see the assumptions contajned in eacl.

These derivations are shown in the following seclion.

\section{Derivation of simpler models}

Consider a small induction motor in which rotor fluxes and variations in electrical frequency can be neglected. A small induction motor model is obtained by setting $T_{0}^{\prime}=0$ and $\omega=$ $\omega$, in Equations (54)-(56), giving

Model in terms of voltage magnit.ude, angle, and frequency

$$
\begin{aligned}
& T_{0}^{\prime} \frac{d V}{d t}=\frac{-V+\left(X^{\prime}+X_{s}\right) \frac{Q_{L}}{V}-\frac{X^{\prime} X_{L}}{V^{3}}\left(P_{L}^{2}+Q_{L}^{2}\right)+\frac{X^{\prime} T_{0}^{\prime}}{V}\left(\left(1-\frac{X^{\prime}}{V^{2}} Q_{L}\right) \frac{d Q_{L}}{d t}-\frac{X^{\prime}}{V^{3}} P_{L} \frac{d P_{L}}{d t}\right)}{\left(1-\frac{X^{\prime}}{V^{\prime}}\left(P_{L}^{2}+Q_{L}^{2}\right)\right)} . \\
& \frac{d \theta}{d t}=\omega-\omega, \\
& \frac{2 H}{\omega_{0}} \frac{d \omega}{d t}=P_{L}-K_{L}\left(\frac{\omega}{\omega_{0}}-\frac{\left(X^{\prime}+X_{0}\right) P_{L} V^{2}+X^{\prime} T_{0}^{\prime}\left(\left(V^{2}+X^{\prime} Q_{L}\right) \frac{d P_{L}}{d t}-X^{\prime} P_{L} \frac{d Q_{L}}{d t}\right)}{\left(V^{4}-X^{\prime 2}\left(P_{L}^{2}+Q_{L}^{2}\right)\right) \frac{X_{I}}{R_{r}}}\right) \\
& +2 H \frac{\left[\left(\left(X^{\prime}+X_{0}\right) P_{L}+X^{\prime} T_{0}^{\prime} \frac{d P_{L}}{d t}\right) 2 V \frac{d V}{d t}+\left(X^{\prime}+X_{0}\right) V^{2} \frac{d P_{L}}{d t}+T_{0}^{\prime} X^{\prime 2}\left(Q_{L} \frac{d^{2} P_{L}}{d t^{2}}-P_{L} \frac{d^{2} Q_{L}}{d t^{2}}\right)\right]}{\left(V^{4}-X^{\prime 2}\left(P_{L}^{2}+Q_{L}^{2}\right)\right) \frac{X_{X}}{R_{*}}} \\
& -2 H \frac{\left(\left(X^{\prime}+X_{0}\right) P_{L} V^{2}+X^{\prime} T_{0}^{\prime}\left(\left(V^{2}+X^{\prime} Q_{L}\right) \frac{d P_{L}}{d t}-X^{\prime} P_{L} \frac{d Q_{L}}{d t}\right)\right)\left(4 V^{3} \frac{d V}{d t}-2 X^{\prime 2}\left(P_{L} \frac{d P_{L}}{d t}+Q_{L} \frac{d Q_{L}}{d t}\right)\right)}{\left(V^{4}-X^{\prime 2}\left(P_{L}^{2}+Q_{L}^{2}\right)\right)^{2} \frac{X_{L}}{R_{X}}}
\end{aligned}
$$


186

$$
\begin{aligned}
& 0=-V+\left(X^{\prime}+X_{0}\right) \frac{Q_{L}}{V}-\frac{X_{1} X^{\prime}}{V^{3}}\left(P_{L}^{2}+Q_{L}^{2}\right) \\
& \frac{d \theta}{d t}=0 \\
& 0=P_{L}-K_{L}\left(1-\frac{\left(X^{\prime}+X_{L}\right) P_{L} V^{2}}{\left(V^{4}-\bar{X}^{\prime 2}\left(P_{L}^{2}+Q_{L}^{2}\right)\right) \frac{X_{I}}{R_{r}}}\right) \\
& +2 H \frac{\left(X^{\prime}+X_{\odot}\right)\left(P_{L} 2 V \frac{d V}{d t}+V^{2} \frac{d P_{L}}{d t}\right)}{\left(V^{4}-X^{\prime 2}\left(P_{L}^{2}+Q_{L}^{2}\right)\right) \frac{X_{I}}{R_{r}}} \\
& -2 H \frac{\left(X^{\prime}+X_{\odot}\right) P_{L} V^{2}\left(4 V^{3} \frac{d V}{d t}-2 X^{\prime 2}\left(P_{L} \frac{d P_{f}}{d t}+Q_{L} \frac{d Q_{L}}{d t}\right)\right)}{\left(V^{4}-X^{\prime 2}\left(P_{L}^{2}+Q_{L}^{2}\right)\right)^{2} \frac{X_{I}}{R_{r}}}
\end{aligned}
$$

Linearization yields

$$
\begin{aligned}
0= & A \Delta V+B \Delta P_{L}+C \Delta Q_{L} \\
0= & D \Delta V+E \Delta P_{L}+F \Delta Q_{L} \\
& +G \frac{d \Delta V}{d t}+H \frac{d \Delta P_{L}}{d t}+I \frac{d \Delta Q_{L}}{d t}
\end{aligned}
$$

Use Equation (61) to eliminate $\Delta Q_{\boldsymbol{L}}$ in Equation (62), giving Morlel assuming $T_{0}^{\prime}=0$ and $\omega=\omega_{s}:$

$$
\begin{aligned}
\Delta P_{L}+T_{p p} \frac{d \Delta P_{L}}{d t} & =K_{p v}\left(\Delta V+T_{p v} \frac{d \Delta V}{d t}\right) \\
\Delta Q_{L} & =K_{q v} \Delta V+K_{q p} \Delta P_{L}
\end{aligned}
$$

Neglecting frequency, this model is almost the same as Model B. This result suggests that Model B captures some of the dynnmic phenomenou associnted with small induction motors. This is consistent, with stuclies performed in [2] in which all measurements were made on small induction motors.

A large induction motor model in which rotor fux dynamics are captured while speed variations are neglected is easily oblained from Equations (45)-(4T) before the frequency variable is introduced. Neglecting $\boldsymbol{X}^{\prime}$ and assuming slip is constant in (45)-(47) yield

$$
\begin{aligned}
& T_{0}^{\prime} \frac{d V}{d t}=-V+X \cdot \frac{Q_{L}}{V} \\
& T_{0}^{\prime} V \frac{d \theta}{d t}=-s \frac{X_{r}}{R_{r}} V+X \cdot \frac{P_{L}}{V}
\end{aligned}
$$

which when solved explicitly for $\boldsymbol{P}_{\mathbf{L}}$ and $\boldsymbol{Q}_{L}$ gives Model assuming $X^{\prime}=0$ and constant. slip:

$$
\begin{aligned}
& Q_{L}=\frac{V^{2}}{\bar{X}_{0}}+\frac{V T_{0}^{\prime}}{\bar{X}_{0}} \frac{d V}{d t} \\
& P_{L}=\frac{s}{\bar{R}_{r}}\left(\frac{X_{r}}{\bar{X}_{0}}\right) V^{2}+\frac{T_{0}^{\prime}}{\bar{X}_{0}} V^{2} \frac{d \theta}{d t}
\end{aligned}
$$

This model is similar in form to Model C and Model D. This result suggests that Model C captures some dynamic characleristics of Iarge induction molors. This is consistent with [7] where it is assumed that the flux dynamics are not negligible.

Another strength of the general model (54)-(56) is that it can be nsed to create new models using whatever assumptions are appropriate for a particular case. For instance, the model in which $X^{\prime}$ is neglected but speed is not neglected is easily oltained. This model is
Model assuming $X^{\prime}=0$ :

$$
\begin{aligned}
T_{\bullet}^{\prime} \frac{d V}{d t}= & -V+X, \frac{Q_{L}}{V} \\
\frac{d \theta}{d t}= & \omega-\omega, \\
\frac{2 H}{\omega_{\bullet}} \frac{d \omega}{d t}= & P_{L}-K_{L}\left(\frac{\omega}{\omega_{0}}-\frac{-X_{\bullet} P_{L} R_{r}}{V^{2} X_{r}}\right) \\
& +2 H \frac{R_{r} X_{\bullet}\left(P_{L} 2 V \frac{d V}{d t}+V^{2} \frac{d P_{T}}{d t}\right)}{V^{4} X_{r}} \\
& -2 H \frac{4 X_{,} P_{L} R_{r}}{V^{3} X_{r}} \frac{d V}{d t}
\end{aligned}
$$

Physically, one might argue that neglecting magnetizing reactance is a better assumption then neglecting leaknge reactances. This model is easily obtained:

Model assuming $X_{s}=X_{r}=X_{m} \rightarrow \infty:$

$$
\begin{aligned}
& 0=Q_{L}-\frac{X^{\prime}}{V^{2}}\left(P_{L}^{2}+Q_{L}^{2}\right) \\
& \frac{d \theta}{d t}=\omega-\omega_{0} \\
& \frac{2 H}{\omega_{s}} \frac{d \omega}{d t}=P_{L}-K_{L}\left(\frac{\omega}{\omega_{*}}-\frac{P_{L} R_{r} V^{2}}{\left(V^{4}-X^{\prime 2}\left(P_{L}^{2}+Q_{L}^{2}\right)\right)}\right) \\
&+2 H \frac{R_{r}\left(P_{L} 2 V \frac{d V}{d t}+V^{2} \frac{d P_{L}}{d t}\right)}{\left(V^{4}-X^{\prime 2}\left(P_{L}^{2}+Q_{L}^{2}\right)\right)}(i 3) \\
&-2 H \frac{P_{L} R_{r} V^{2}\left(4 V^{3} \frac{d V}{d t}-2 X^{\prime 2}\left(P_{L} \frac{d P_{L}}{d t}+Q_{L} \frac{d Q_{L}}{d t}\right)\right)}{\left(V^{4}-X^{\prime 2}\left(P_{L}^{2}+Q_{L}^{2}\right)\right)^{2}}
\end{aligned}
$$

In addition to these types of models, one can formulale quasi-static frequency-depentent models in which all tim. derivatives are considered negligible (except the definition of frequency, $\omega=\omega_{s}+d \theta / d t$ ). For instance. consider such in model in which all reactances are neglected. This crude model is equivalent to modeling the motor as a slip-dependent resistor. 'This model is easily obtained:

Quasi-static frequency-dependent model with $X^{\prime}=0$, $\bar{X}_{1}=\bar{X}_{r}=\bar{X}_{m} \rightarrow \infty:$

$$
\begin{aligned}
& Q_{L}=0 \\
& P_{L}=\frac{V^{2} K_{L}}{\left(V^{2}+\bar{K}_{L} \tilde{R}_{r}\right)} \frac{\omega}{\omega_{L}}
\end{aligned}
$$

This model resembles the "stalic" motor model used in the EPRI LOADSYN package. A similar model can be developed by neglecting transient effects of the shunt reactances but including the leakage reactances. This model is casily olthaincd:

Quasi-static frequency-depentlent model with $\bar{X}_{1}=\bar{X}_{r}=\bar{X}_{m} \rightarrow \infty$

$$
\begin{aligned}
& 0=V^{2} Q_{L}-X^{\prime}\left(P_{L}^{2}+Q_{L}^{2}\right) \\
& 0=\left(P_{L}-K_{L} \frac{\omega}{\omega_{0}}\right)\left(V^{4}-X^{\prime 2}\left(P_{L}^{2}+Q_{L}^{2}\right)\right)-P_{L} R_{r} V^{2}(i \&)
\end{aligned}
$$

While this model is not in as simple a form as model ( 75$)$ ( $(\mathrm{T} 6)$, it is another frequency-dependent induction motor modelbased load model that can be considered.

Through all these examples it is clear that model (54) (56) is useful, despite its unusual and complex appearance. 11. represents a detailed model of an induction motor in terms of 
bus variables. Many simpler models can be obtained from this model by applying certain constraints.

\section{Practical issues}

T'he implicit form of some of the models derived in the previons section gives rise to questions about their implementation. Recall the general form of a detailed model of power systems willout stator/network transients:

$$
\begin{aligned}
\frac{d x}{d t} & =f\left(x, I_{d}, I_{q}, V\right) \\
0 & =I_{d}-g_{d}(x, V, \theta) \\
0 & =I_{q}-g_{q}(x, V, \theta) \\
0 & =P_{L}-g_{P}(x, V, \theta) \\
0 & =Q_{L}-g_{q}(x, V, \theta)
\end{aligned}
$$

where the $x$ variables correspond to dynamic generator states, $I d$ and $I q$ are generator stator currents, $V$ and $\theta$ are vectors of all bus voltages and angles, and $P_{L}$ and $Q_{L}$ are the load power relations. When $P_{L}$ and $Q_{L}$ are expressed in terms of $V$, then one can eliminate the algebraic equations provided a solution exists. For example, if $\boldsymbol{P}_{\boldsymbol{L}}$ and $\boldsymbol{Q}_{\boldsymbol{L}}$ are constants or functions of $V$. then Equations (82) and (83) must be solved for $V$ and $\theta$ so that all algebraic variables can be eliminated.

A clifferent approach nust, be applied when the load equations are dynanic and implicitly defined. In general, the load constraints derived in this paper are of the form

$$
\begin{aligned}
0 & =h_{V}\left(P_{L}, Q_{L}, V, \omega, \frac{d V}{d t}, \frac{d P_{L}}{d t}, \frac{d Q_{L}}{d t}\right) \\
0 & =h_{\theta}\left(\omega, \frac{d \theta}{d t}\right) \\
0 & =h_{\omega}\left(P_{L}, Q_{L}, V, \omega, \frac{d V}{d t}, \frac{d \omega}{d t}, \frac{d P_{L}}{d t}, \frac{d Q_{L}}{d t}\right)
\end{aligned}
$$

With $V$ and $\theta$ state variables, $I_{d}$ and $I_{q}$ are explicitly defined in terms of state variables and may be substituted into the generator dynamic equations, $P_{L}$ and $Q_{L}$ must be replaced in Equations (84) - (86) using Equations (82) and (83). This results in a well-defined system in terms of state variables.

The resulting system will be extremely nonlinear. In general, the load differential equations will be expressed in an implicit form containing the derivatives of different state variables. $\mathrm{Al}$ though there has been work in the area of general implicit difrerential/algebraic equations with respect to power system morlels [13], it is not clear that this level of sophistication is lesired or necessary. Since the actual load is not an induction motor, one mist decide whether or not the use of an implicit nonlinear system model is worth the increased computational requircments.

One may approach the problem differently. The reason for deriving model (54)-(56) was the desire to have an induction motor-based loarl model in terms of physical bus variables, aclive and reactive powers, voltage magnitude, angle, and freunency. 'These requirements are practical for power engineers but are somewhat unusual for electrical engineers. An average electricnl engineer would normally model an unknown load by a. 'Thévenin equivalent circuit. In the case of induction motor londs, this simplifies the model significantly; the third order induction motor model is already in the form of a Thévenin equivalent circuit. Equations $(27)-(30)$ and $(33)$ are represented by the dynanic Thévenin equivalent circuit shown in
Figure 1. This is a dynamic circuit because the voltage source in the circuit has dynamics described by differential equations.

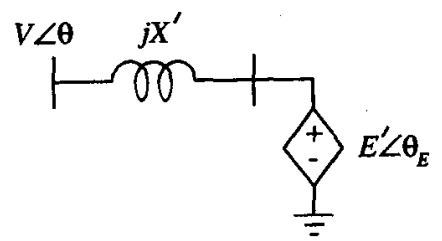

Figure 1: Dynamic Thévenin equivalent circuit

The majn drawback to using a dynanic Thévenin eyfivalen model is that obtaining data for the series innpedance and internal source may be difficult. Model (51) (56) may be useful in this respect. Since it is described solely in terms of bus variables, it might be used to estimate parameter valnes, which, il turn, can be used to describe the Thévenin equivalent circuits.

An advantage of conceptually thinking aboul louks as dynamic equivalent circuits is that some of the "generic" loal models are already in this form [5, 6]. The specilic rase of Model $F$ used in [G] is simply a resistor whose value of conductance is governed by a differential equalion. In general, Model $\mathrm{F}$ can be described as a nonlinear impedance whose val. ues associated with conductance and susceptance, $x$ and $y$, ar governed by differential equations. Both of these models are easily conceived in terms of dyuanic equivalent circuits.

Using these concepts, a simpler system model results:

$$
\begin{aligned}
\frac{d x}{d t} & =f\left(x, I_{d}, I_{q}, V\right) \\
0 & =I_{d}-g_{d}(x, V, \theta) \\
0 & =I_{q}-g_{q}(x, V, \theta) \\
0 & =I_{d}-g_{G P}(x, V, \theta) \\
0 & =I_{Q}-g_{G Q}(x, V, \theta) \\
0 & =I_{L D}-g_{L P}(V, \theta) \\
0 & =I_{L Q}-g_{L Q}(V, \theta) \\
0 & =I_{L D}-g_{D}(y, V, \theta) \\
0 & =I_{L Q}-g_{Q}(y, V, \theta) \\
\frac{d y}{d t} & =h\left(y, I_{L D}, I_{L Q}\right)
\end{aligned}
$$

where $I_{L D}$ and $I_{L Q}$ are the load currents, and $y$ is the vector of load state variables. Note that the dimension of $V$ (and $\theta$ ) is equal to the sum of the dimensions $I_{d}$ and $I_{L D}$. I'sing the current formulation, the algebraic equations are linear: they car be eliminated in a standard fashion. This system model is simple.

\section{Conclusions}

In this paper we develop a P.Q dynanic load model based on induction motor characteristics. After neglecting stator transients and stator resistance, this model is an exact representation of a third-order induction motor. 'The state variables are in terms of meaningful bus variables: voltage magnit.nde. angle and frequency. This model is used to justify other models that appear in the literature which have not been rigoronsly derived. Model $B$ and Model $C$, which appear contralictory, are explained. They capture difTerent phenomenon. M.lodel B captures some of the dymanic characteristics associated with small 
188

induction motors, while Model C captures some of the dynamic characteristics associated with large induction motors. These widely diflerent characteristics lave been examined in $[14,15]$ For au engineer to use such a model it is helpful to understand the assumptions that are implicit in the model.

Every l', Q load model based on induction motors can be derived from (54)-(56) with the appropriate assumptions. We also demonstrate how new models can be easily generated. Additional research is required to determine exactly which as sumptions are suitable for a particular type of study.

Practical issues involving the implementation of load models are addressed. In particnlar, models that are implicitly defined wit. I time derivatives of active and reactive porvers are likely t.o be too difficult to implement to be of practical use.

We emphasize that if one relaxes the requirement that loads be described dynamically in terms of power and are instead thought of dynamic circuits relating voltages and currents, 1. he'll modeling and analysis is simplified. These dynamic circuits can include (nonlinear) resistances, reactances, vollage and current sources whose parameters may be governed by differential equations. Many of the dynamic load models in use can be directly implemented in this fashion.

\section{Acknowledgements}

The althors thank Professor 'Thomas Overbye for his helpful silggestions. Tlis work was supported in part by the Grainger fonmlation Enclowments to the University of Illinois, the University of Illinois Power Affiliates Program, and EPRI project 8() $\mid 11-21$.

\section{References}

[I] K. Walve, "Modelling of power system components at sever disturbances," CHGRE paper 38-18, 1986.

[2] D. Karlsson and T. Pehrsson, "A dynamic power system load model and methods for load model parameter estimaiion," in Technical Report No. 22L, Chalmers University of Technology, Goteborg, Sweden, 1985.

[3] C'.L. DeMarco and A.R. Bergen, "A security measure for random load disturbances in nonlinear power system modHa." IEEE Trans. Circuits Syst., vol. CAS-34 pp. 15461557. December 1987

[4] D. Hill, "Nonlinear dynamic load models with recovery for voltage stability st.udies," IEEE Trans. Power Syst., vol 8, no. 1, pp. 166-176, February 1993.

[5] W. $\mathrm{X}_{\|}$and $\mathrm{Y}$. Mansour, "Voltage stability analysis using generic dynamic load models," paper 93 WM 185.9 PWRS presented at the 1993 PES Winter Meeting, Columbus, OH, January 1993.

[6] M.K. Pal, "Voltage stability conditions considering load characteristics," IEEE trans. Power Syst., vol. $\mathfrak{\tau}$, no. 1 , pp. 2-13-249, l'ebruary 1992.

[i] K. Jimma. A. Tomac, K. Vu, and C.-C. Liu, "A study of dynamic loak models for voltage collapse analysis," Proc. Bulk Power System Voltage Phenomena II Voltage Stabil ity and Security, Deep Creek Lake, MD, August 1991.

[8] IEFE Task Force, "Load representation for dynamic performance analysis," IEEE Trans. Power Syst., vol. 8, no. 2 , pp. 4T2-482, May 1993

[9] W.W. Price, K.A. Wirgau, A. Murdoch, and F. Nozari "Load modeling for power flow and transient stability computer studies: Summary report." EPRI EL-5003 Project 849-7 Final Report, Palo Alto, CA, January 198i.
[10] I. Dobson and H.D. Chiang, "Towards a theory of voltage collapse in electric power systems." System and control letters, pp. 253-262, 1989.

[11] C.L. DeMarco and I'.J. Overbye, "An energy based sccurily measure for assessing vulnerability lo vollage collapse," IEEE Trans. Power Syst., vol, 5 pp 419-427. May 1990.

[12] A.R. Bergen and D.J. Hill, "A structure preserving moklel for power system stability studies." IEEE Trans, Power Appar. Syst., vol PAS-100. PP. 25-33, Jalluary 1981.

[13] M. Crow, Waveform relaxation methods for the simtration of systems of differential/algebraic equations with applications to electric power systems. Jh.D. dissertation, $I_{n} i$ versity of Illinois. Utbana-Champaign. IL 1990.

[14] S. Ahmed-Zaid and M. 'Taleb. "Structural modeling of small and large induction machines using integral manifolds," IEEE Trans, on Energy Conversion, vol. 6, no. 3. Sept. 1991, pp. 529-535.

[15] S. Ahmed-Zaid and M. 'Taleb. "First-orsler Iuduction machine models near voltage collapse", Proc. Bulk Power System Voltage Phenomena II Voltage Stability and Se. curity, Deep Creck Lake, MD, August 1991.

[16] T. Van Cutsem. "Dynamic and static aspects of voltage collapse," P'roceedings of Juternational Workshop on 13 ulk Power System Voltage Phenomena: Voltage Stability anl Security, Potosi, MO, Sept. 1988.

[17] D. Larlsson and D.J. Hill, "Nodelling and identification of nonlinear loads iu power systems," IEEE Publication 93WN 1TI-9 PWRS

[18] D.J. Hill and 1.A. Hiskens, "Dynamic analysis of rolinge collapse in power systems," Proceedings of the $31 \mathrm{~s} 1 \mathrm{(!I})($ : Tuscon, AZ, December 1992.

Bernard C. Lesicutro $(S \times 8, M 93)$ received his B.S., M.S., and Ph.D. degrees in electrical engincering from the l'niversity of Illinois at Urbana-Cbampaign in 1986, 1988, ancl 1993 respectively. His research interests include machine mokling ant power system dynamics, stability and control. IJe is a member of Eta Kappa Nu and a student member of the IELE:

Peter W. Sauer(S'73,M'T7,SN'82,F'93) was born in Wimon: Minnesota on September 20, 1946. He received the B.S. degree in electrical engineering from the Iniversily of Missonsi at Rolla, and the M.S. and Ph.D degrees in electrical engimering from Purdue (Iniversily in 1969, 1971 and 1975 respertively. He is currently a Grainger Assoriate and a Professor of Electrical Engineering at the University of Illinois at IrbanaChampaign. He is a member of Eta Kiappa $\mathrm{Nu}$, Sigma Xi, lhi liappa Phi, IELE and is a registered Professional Engincer in the Commonvealth of Virginia and the State of Illinois.

M. A. Pai(S'61,M'61.SM'72.F'86) received his Baclielor's degree in electrical engineering from the liniversily of Mulras, India (1953) and M.S. (1958) and J'h.D) (1961) from the (lniversity of California Berkeley. Ile was on the Faculty of I.I.T. Kanpur from 1963 to 1981. Since 198] he is a Professor of Electrical and Computer Engineering at the I'niversily of Illinois at Urbana-Champaign. His research Interests are power systcm dynamics, stability and control. He is fellow of the Judian $\mathrm{Na}$ tional Science Academy, Institution of Engineers (India) and the IEEE. 


\section{Discussion}

M. K. Pal (Consultant, Edison, NJ): This paper relates the various load models, some of which have recently been reported in the literature on voltage stability, to the well known thirdorder induction motor model. The authors suggest the desirability of having load models that are representable in terms of measurable bus quantities such as power, voltage, current, etc.

First, we would like to point out that models other than the third-order induction motor model considered in the paper can also be transformed to any of the models B - E (equations 3-10). In the maze of the algebra included in the paper hides the important fact that the models B - F are actually alternative descriptions of the same model (not necessarily the same load). Note that these are first-order models, whereas the induction motor model used by the authors as the starting point (equations 29-31) is a third-order model. Therefore, after transforming the model to that given by equations (54)-(56), they had to apply various assumptions (which, in effect, reduced the order of the model) in order to derive the models B - E. We note that the authors' objective was to justify these models by showing that they can be derived from a thirdorder induction motor model by applying various assumptions. The authors' analysis also shows the validity of the models to represent induction motor loads under certain conditions. We agree that most of these models were probably derived from intuition, although some were reported to have been based on field measurements.

We now show that, starting with the simple first-order induction motor model, which is the simplified equivalent circuit along with the equation of motion (the so-called slip model), all the models B - E follow by applying simple transformation. The detail of the algebra, which is quite simple, is omitted here. If one writes the expressions for the real and reactive powers in terms of the bus voltage and the equivalent circuit parameters, takes the derivatives, and substitutes the derivative of slip from the equation of motion, one comes up with

$$
\begin{aligned}
& \dot{P}=f_{P}(P, V)+g_{P}(P, V) \dot{V} \\
& \dot{Q}=f_{Q}(Q, V)+g_{Q}(Q, V) \dot{V}
\end{aligned}
$$

which can also be written in the form of model $\mathrm{E}$ (equations 9 10) of the paper. Note that these two equations are not independent.

Expressing the motor power in terms of the system quantities (bus voltage and angle), taking the derivatives and substituting for $\mathbf{P}$ and $\dot{Q}$ in (1) and (2), one can obtain

$$
\begin{aligned}
& P=P(V)+k_{1}(V, \theta) \dot{\theta}+k_{2}(V, \theta) \dot{V} \\
& Q=Q(V)+k_{3}(V, \theta) \dot{\theta}+k_{4}(V, \theta) \dot{V}
\end{aligned}
$$

In deriving equations (3) and (4) the variation of voltages and angles of buses other than the load bus has been neglected. A similar assumption is implicit in the authors' derivation also. Note that equations (1) - (4) encompass the models B - D of the paper. Any other first-order physically based load model can also be transformed to the above forms, (1) - (4), in a similar manner. Note that all the coefficients in the load models described by bus variables are, in general, functions of these variables. These parameters cannot be chosen arbitrarily. Great care needs to be exercised in selecting the parameter values, whether analytically or from actual measurements, so that stability information obtained from these models is physically justified [A]

We would like to make some general remarks on the models B - E (equations 3-10), and the model derived from the third order induction motor model (equations 54-56). In stability studies the network model is simplified by eliminating the terms that give rise to the high frequency electrical transients, and hence the bus variables such as voltage, angle, real and reactive power, are not true state variables. They can have discontinuities following a system disturbance. Device models using time derivatives of these variables are neither suitable nor desifable for general stability studies. Also, in the models that are described by bus variables, the number of variables involving time derivatives will invariably be higher than that in the corresponding models derived from physical laws (such as the familiar induction motor model), unless certain terms are dropped arbitrarily. Note that in the model described by equations (54) - (56), the number of variables involving time derivatives is seven as opposed to three in the parent model described by equations (29) - (31). (Actually, the number of independent variables is still three.)

It may be convenient to derive load models in the bus variable form from field measurements. However, to be of practical use in power system analyses, these models would have to be transformed to state variable forms $[4, \mathrm{~B}, \mathrm{C}]$. This transformation would generally be considerably more difficult than the reverse transformation (i.e., from the state variable to bus variable form). Also, in the transformation the resulting state variables will often lose physical significance.

Models of individual load devices are already available in state variable forms, which lend them to Thevenin equivalent circuit representation as shown in Fig. 1 of the paper. Aggregate load models derived from field measurements need not be in the bus variable form. Derivation of aggregate load model directly in the state variable form is practical.

It is not clear why the authors think that "traditional induction motor variables lack physical significance in a power system." Using their example, if the load is actually an induction motor load, "slip" is clearly defined. For loads other than induction motor, "slip" can be given some other, valid, interpretation, depending on the load, such as a variable conductance. A detailed induction motor model would probably be used only to represent an actual induction motor or a group of motors. The power engineers need not feel uncomfortable with the traditional two-axis induction machine models described in terms of flux linkages, internal voltages, slip, etc., if they are happy with similar models for synchronous machines.

The load model used in Reference 6 of the paper was not a new model. It is actually the induction motor slip model with constant load torque and the leakage reactance set to zero. (This is clarified in $[\mathrm{A}]$.) The model captures the essential dynamic characteristic, affecting voltage stability, of a variety of load devices. It was used to provide insights and explain the various phenomena in voltage stability. The model is given in [A] in a more general form as stated in equation (5).

$$
T_{L p} \dot{G}=P(V)-V_{o}^{2}\left(V / V_{o}\right)^{n} G
$$

with $\mathrm{n} \geq 1.0$, for the real power, and similarly for the reactive power. Note the limit specified on the value of the index $n$. The model is not valid for values of $n$ less than 1 [D]. Note the similarity of (5) to the "generic" model given in Reference 5 of the paper, except that in [5] the limit on the value of $n$ was not recognized. 
190

Most of the load models discussed in this paper as well as in the references listed in the paper were proposed and/or used in voltage stability studies. A comment on the requirement and adequacy of load modeling in voltage stability studies might, therefore, be in order. Except in situations where the load response is fast compared to the speed of response of voltage control, load modeling detail has no bearing on the outcome of dynamic voltage stability studies [A]. All the conclusions can be correctly drawn from steady-state analyses using steady-state criteria after properly reflecting the steady-state load characteristics in the system model. When the load exhibits fast response characteristics, a detailed dynamic analysis employing actual models of the individual load devices would be needed.

[A] M.K. Pal, "Voltage Stability: Analysis Needs, Modelling Requirement and Modelling Adequacy," IEE Proc. C, Vol.140, No.4, pp. 279-286, July 1993

[B] M.K. Pal, discussion of Reference 4 of the paper.

[C] M.K. Pal, discussion of Reference 17 of the paper.

[D] M.K. Pal, discussion of Reference 5 of the paper.

Manuscript received March 7, 1994.

B.C. LESIEUTRE, P.W. SAUER, M.A. PAI: We thank Dr. $\mathrm{Pal}$ for his insightful comments on our paper. We agree that a model expressed in terms of bus variables is not necessarily the most useful, we only note that there is a desire to model a load in terms of measurable quantities. In our paper we do state that an induction motor can be represented simply by dynamic Thévenin equivalent circuit. This representation is assuredly more accurate a model than those discussed in detail in that paper because it is an exact representation of the third-order model. Certainly one should not feel incomfortable with this model as it is similar to the synchronous machine models that we commonly use. If one accepts such a model, the challenge is to determine the internal states and their dynamics.

Dr. Pal points out that Models B-E presented in the paper are similar in form and that there is a general form which en compasses them all. Specifically, without any derivation whatsoever, one can propose

$$
\begin{aligned}
T_{P P} \frac{d P_{L}}{d t}+P_{L} & =P_{o}(V)+K_{p V}(V) \frac{d V}{d t}+K_{p f}(V) \frac{d \theta}{d t}(1) \\
T_{q p} \frac{d Q_{L}}{d t}+Q_{L} & =Q_{o}(V)+K_{q V}(V) \frac{d V}{d t}+K_{q f}(V) \frac{d \theta}{d t}(2)
\end{aligned}
$$

By appropriately choosing the parameters, Models B-E do fit this form. Furthermore he demonstrates that a simple firstorder model including slip dynamics can be transformed into this general form. One may wonder then why we bother starting the analysis with a third-order model? Not all of the models presented in the paper capture slip dynamics. Model D is argued to capture rotor flux dynamics, and indeed, in Reference (7) of the paper the authors point out that Model D is inappropriate when rotor speed dynamics are important. It does not capture slip dynamics. Determining which parameters in the general form are dominant based on physical properties of the motor is essential. We remind the reader that all linear systems have the same form; it is the parameters that define the behavior. In this paper we relate the dominant parameters in models that appear in the literature to standard physical parameters with which we describe induction motors. We ac-

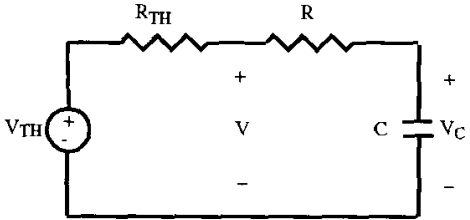

Figure 1: RC circuit with a dynamic Thévenin equivalent

knowledge that a dynamic slip model for an induction motor expressed in terms of bus variables has a similar form but we point out that a more detailed model expressed in terms of bus variables does not without simplifying assumptions.

In response to Dr. Pal's comments on the suitability of using "non-true" state variables, consider the circuit shown in Figure 1 consisting of resistor and capacitor connected to a linear network represented by a Thévenin equivalent.

Choosing the capacitor voltage to be the state variable we obtain the usual dynamic description of this circuit:

$$
C\left(R+R_{T H}\right) \frac{d V_{c}}{d t}=-V_{c}+V_{T H}
$$

Choosing the voltage across the capacitor and resistor, $V$, to be the state variable we obtain

$$
\begin{aligned}
C\left(R+R_{T H}\right) \frac{d V}{d t}= & -V+V_{T H}+C R \frac{d V_{T H}}{d t} \\
& +\frac{C R}{R_{T H}}\left(V-V_{T H}\right) \frac{d R_{T H}}{d t} \\
& -C\left(V-V_{T H}\right) \frac{d R}{d t}
\end{aligned}
$$

These two representations are related by

$$
V=\frac{R V_{T H}+R_{T H} V_{c}}{R+R_{T H}}
$$

Both representations give identical results and both are equally valid descriptions of the system. The confusion arises from not understanding how $V$ can change instantaneously in Equation (4). The resistor, $R$, is truly a resistor and its derivative can be ignored in Equation (4); however, $V_{T H}$ and $R_{T H}$ are equivalent circuit parameters whose derivatives should not be ignored. If there is a discontinuous change in the linear network (applying or clearing of a fault, for instance), then the Thévenin equivalent circuit parameters will change discontinuously. This will be reflected in Equation (4) by a change in the time constant, and the addition of impulses to the input. We remind the reader that an impulse can cause a state variable to change discontinuously. We emphasize that this is true of state variables in general; even the voltage across the capacitor in the Figure 1 can change instantaneously if subjected to an impulse.

From a practical standpoint we agree that a model with internal state variables is more convenient in that it is relatively impervious to discontinuous changes that appear in the network. In practice, one could keep track of $R_{T H}$ and go through the process of resolving singularities when it changes discontinuously. The proper treatment of $d V_{T H} / d t$ in the example above and time derivatives of Real and Reactive power is discussed in the paper. We specifically discuss how they can be treated and identify problems they pose. They do not appear in many of the simple load models because the coefficients that multiply 
them disappear when certain physical parameters of the motor are neglected. We suggest the use of a dynamic Thévenin equivalent circuit to avoid the inconvenience associated with resolving time derivatives in power and also because it is a more accurate model for the motor. If all types of loads can be similarly represented then load model aggregation should be simplified.

Manuscript received April 18, 1994. 